Article

\title{
Study the Formation Process of Cuboid Microprotrusion by Glass Molding Process ${ }^{\dagger}$
}

\author{
Tao Wang ${ }^{1}$, Tianfeng Zhou ${ }^{2}$, Jing Chen ${ }^{1, *}$ and Lu Song ${ }^{1}$ \\ 1 National Key Laboratory of Science and Technology on Micro/Nano Fabrication, Peking University, \\ Beijing 100871, China; t.wang2010@pku.edu.cn (T.W.); l.song@pku.edu.cn (L.S.) \\ 2 Key laboratory of Fundamental Science for Advanced Machining, Beijing Institute of Technology, \\ Beijing 100081, China; zhoutf@bit.edu.cn \\ * Correspondence: j.chen@pku.edu.cn; Tel.: +86-10-6726-6595 \\ + This paper is an extended version of our paper published in the 6th Optofluidics 2016 Conference, \\ 24-27 July 2016, Beijing, China.
}

Academic Editor: Ai Qun Liu

Received: 27 November 2016; Accepted: 10 February 2017; Published: 23 February 2017

\begin{abstract}
This paper investigates the formation process of a typical microstructure in the glass microfluidic chip, i.e., cuboid microprotrusion, by the soda-lime glass molding process (GMP). The finite element models on the platform Abaqus/Standard were established for simulating the glass molding process. The glass viscoelasticity at pressing temperature was described by the General Maxwell model. The influence of the temperature, aspect ratio and side wall angle on the replication ratio was investigated, and the corresponding predicted molded profiles were demonstrated as well. The established simulation model was verified by experimental results eventually. It could provide a fundamental experience for optimizing glass molding parameters to fabricate microstructures on glass chips.
\end{abstract}

Keywords: glass molding process; finite element modelling; microprotrusion

\section{Introduction}

Compared with polymer microfluidic devices, devices made by glass are proven to be superior in applications in the biology and chemistry fields due to its high transparency, chemical stability and good biocompatibility [1]. In order to achieve the widespread application of glass microfluidic chips, many researchers have been exploring the field of microstructure fabrication techniques on glass, and the conventional approaches can be classified into four categories: wet etching, dry etching, laser processing and mechanical processing. Chen et al. [2] utilized the wet etching method to fabricate a microstructure in soda-lime glass, and a smooth surface microchannel with a depth of more than $110 \mu \mathrm{m}$ was achieved after $2 \mathrm{~h}$ of etching. However, wet etching is limited to being isotropic and is difficult in high-precision dimension reproducibility due to undercutting. In addition, a metal or Si layer is usually required as the etch mask. Park et al. [3] presented a deep reactive ion etching (DRIE) process of the borosilicate glass using the $\mathrm{SF}_{6}$ and $\mathrm{SF}_{6} /$ Ar inductively coupled plasmas; the influence of the etching rate by various process parameters such as the gas chemistry, the gas flow ratio, the top electrode power, and the bottom electrode power was studied. However, the dry etching method suffered from a low etching rate and low etching selectivity between the glass and photoresists, and the cost was relatively high. Nieto et al. [4] developed a laser-based technique for fabricating microfluidic microchips on soda-lime glass substrates, and the manufactured chips were tested with tumor cells (Hec 1A) after being functionalized with an epithelial cell adhesion molecule (EpCAM) antibody coating. However, the laser method often suffered from microcracks and other collateral damage. Lin et al. [5] used an ultra-precision machining method to fabricate cross-junction channels $(14 \mu \mathrm{m}$ 
wide and $28 \mu \mathrm{m}$ deep) with a three dimensional (3D) triangle cross-section. However, the minimum size of the mechanical workability depends on the tool shape, and it is hard to achieve a tool diameter smaller than $50 \mu \mathrm{m}$. In addition, it usually suffered from severe tool wear.

As an effective high-volume and net-shape fabrication method, precision glass molding process technology has been proven to be a potential approach for fabricating microstructures on glass [6] in the optical application field. It is widely utilized to fabricate aspherical glass lenses and periodic microstructures with different pitch sizes, such as Fresnel lenses [7]. Sharp-angled cross-sections and curve surface structures were investigated by experiments and the finite element method (FEM) [8-11], and there are some papers about developing a glass constitutive model [12,13] during the molding process as well.

In terms of cuboid protrusion on microfluidic glass chips, it is an important structure for microscale filters. Chen et al. developed weir-type crossflow filtration microchips for the separation and collection of white blood cells (WBCs) and red blood cells (RBCs) in parallel [14]. Ji et al. designed a weir in microfilter chips, and imposed a cutoff size of $3.5 \mu \mathrm{m}$ to selectively trap WBCs $[15,16]$. It is worth pointing out that they are all silicon-based microfilters, and the fabrication of protrusions on microfluidic glass chips has rarely been reported before. Since molding approaches have many advantages compared to conventional fabricating methods, e.g., high efficiency, low cost and good surface quality, exploring the molding of cuboid microprotrusions on glass can create a solid foundation for the widespread application of glass microfluidic chips.

This paper aims to understand the formation process of cuboid microprotrusions by glass molding process (GMP). First, a simulation model for GMP was established, which considered glass viscoelasticity, and the deformation process was analyzed; then the influence of the pressing temperature, aspect ratio (groove height/width) and side wall angle were studied based on the established models. Finally, the experimental results were presented, and the corresponding simulation models were verified quantitatively. The research could provide fundamental knowledge for optimizing molding parameters.

\section{Experiment Setup}

All test glass were molded on the ultraprecision glass molding machine, PFLF7-60A (SYS Corp., Osaka, Japan), which can operate between 20 and $750{ }^{\circ} \mathrm{C}$. The glass molding process can be schematically illustrated in Figure 1. Before experiment, nitrogen gas was utilized to purge the air to protect the molds from oxidation at high temperature. In GMP, the mold and the platens are heated by infrared lamp to above $50-100{ }^{\circ} \mathrm{C}$ of glass transition temperature $\left(T_{\mathrm{g}}\right)$ for about $180 \mathrm{~s}$. Since glass is transparent in infrared light, it cannot be directly heated by the infrared lamp, but instead, has to be indirectly heated by the core mold and the surrounding gas. Then, pressing is performed to form the microstructure on the glass for $60 \mathrm{~s}$. After that, the annealing is conducted to release the internal stress for $180 \mathrm{~s}$, and in the meantime, small pressure is kept to facilitate the shape transferability. Finally, the molded glass preform is fast cooled to room temperature by water-cooling for $120 \mathrm{~s}$. After demolding, the microstructure on the glass is obtained. The typical evolution of temperature and pressure during GMP cycle is shown in Figure 1.

As for the glass preform material, since the soda-lime glass slides have been used by biomedical researchers to conduct experiments for decades, and it is inexpensive which is beneficial to reduce the whole fabrication cost, it is used in the research as glass preform. The upper and lower platens are made of tungsten carbide (WC) due to its high stiffness and no adhesion characteristics.

The main morphology of the core mold for swell molding is shown in Figure 2. It is fabricated by inductively coupled plasma (ICP) etching technology. Figure $2 \mathrm{a}$ is the scanning electron microscopic (SEM) photo of the groove area on the core mold. In order to demonstrate more details about the groove, the section profile of the second groove is extracted by VK-X200 3D Laser Scanning Microscope (Keyence Co., Ltd., Osaka, Japan ) and shown in Figure 2b, it indicates that the top area is smooth (less than $5 \mathrm{~nm}$ ), the bottom surface is relative rough. The width of the three grooves are 200,100 and 
$50 \mu \mathrm{m}$, and all their depths are around $22 \mu \mathrm{m}$. In addition, the groove wall is not critically vertical which can make the demolding process easy. The morphology of molded glass profile was obtain by Olympus Lext OLS4100 (Olympus Corp., Tokyo, Japan). In predicted results, the filling ratio is defined by dividing the dash area $S_{\mathrm{AED}}$ (molded microstructures) by the area of the rectangle area $S_{\mathrm{ABCD}}$ (the mold), as shown in the Figure 3. The aspect ratio of the mold $r_{\mathrm{a}}$ is defined by $L_{\mathrm{AB}} / L_{\mathrm{BC}}$, and the side wall angle $\theta$ is defined by $\angle \mathrm{BAD}$.
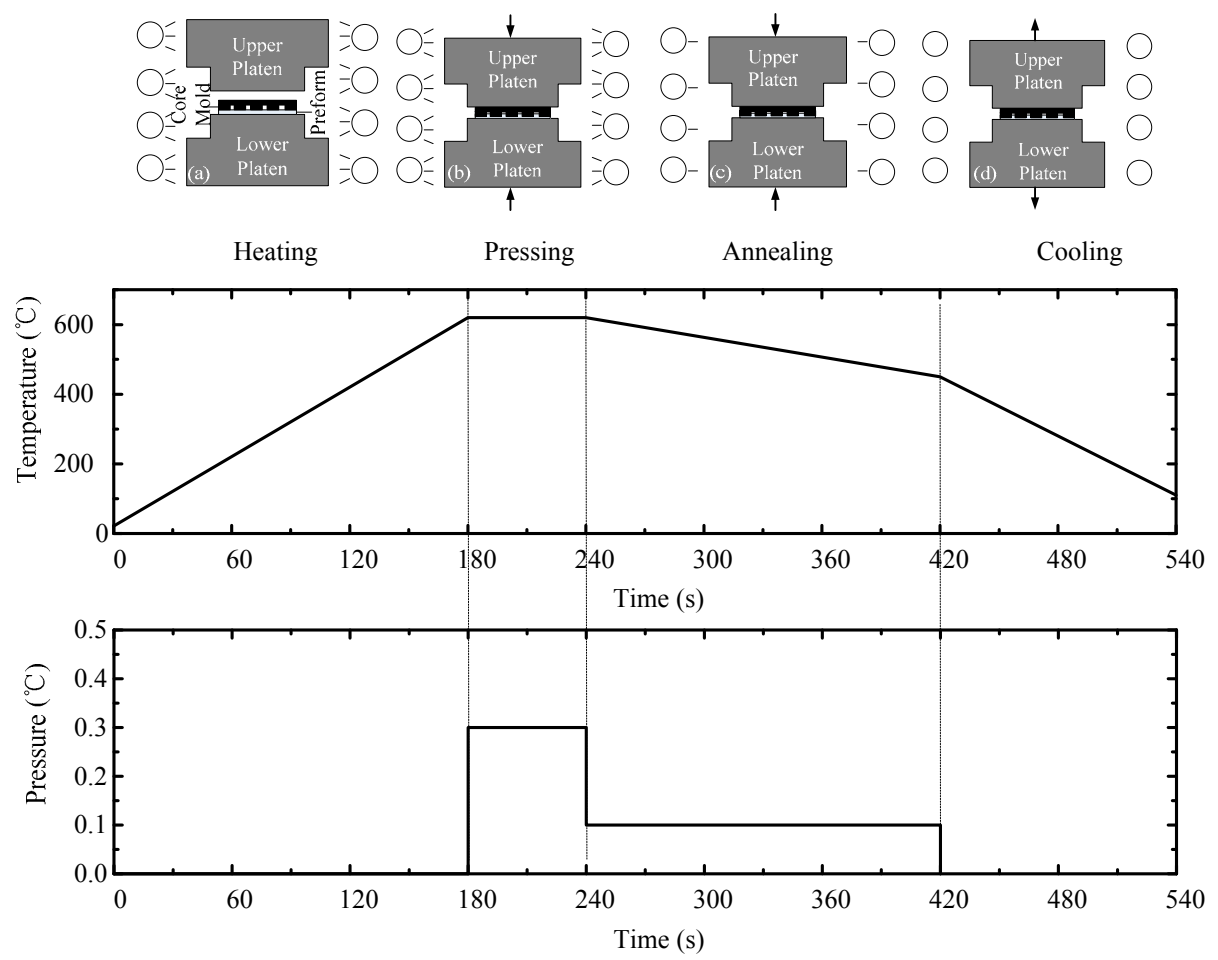

Figure 1. The typical evolution of temperature and pressure during glass molding process (GMP) cycle.

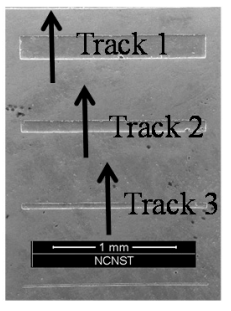

(a)

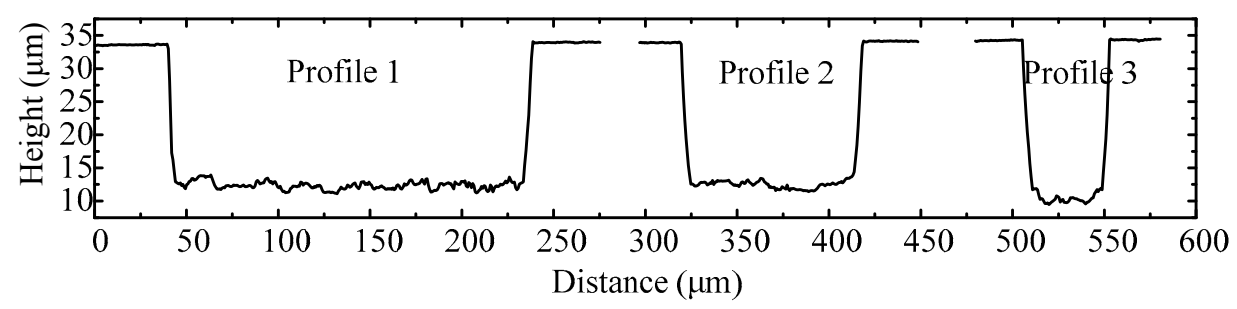

(b)

Figure 2. The morphology of the core mold. (a) Scanning electron microscopic (SEM) photo; (b) profiles along the track.

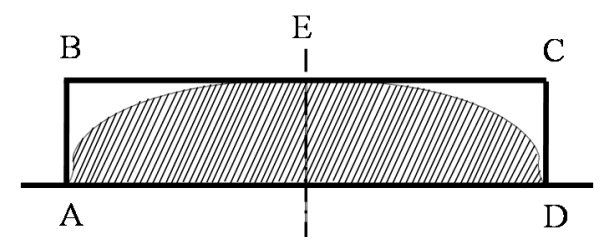

Figure 3. Schematic diagram of the filling ratio (dashed area divided by $S_{\mathrm{ABCD}}$ ). 


\section{Modeling Process}

All the simulation models were established in the commercial finite element software Abaqus/Standard. Since the molding speed is relatively slow compared to other machining processes, the GMP is regarded as a quasi-static process. The GMP consists of four stages, i.e., heating, pressing, annealing and cooling. In order to predict the accurate molded shape, the whole GMP should be simulated in a row. However, it is still a challenge to simulate the entire model of a millimeter-scale object surrounded by micro-/submicrometer-scale structures. In this paper, only the pressing stage was simulated for simplicity, and all the molds and preforms were assumed to maintain a constant temperature, which is tens of degrees centigrade above its transition temperature.

At the pressing condition, the preform demonstrated high viscoelasticity, which is a timedependent response of a material to stress or strain, and they are characterized by creep and stress relaxation behavior. Since the Generalized Maxwell model is proved to be superior to other constitutive models, such as the simple Maxwell model, Kelvin model and Burgers model, it is used to describe creep and stress relaxation in the viscoelastic deformation of glass in the pressing process [17]. In this paper, a six-pair Generalized Maxwell model is used as the constitutive model, and is shown in Figure 4.

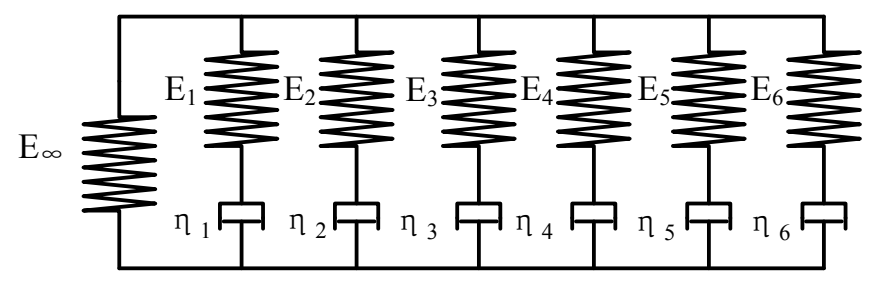

Figure 4. The schematic diagram of Generalized Maxwell model.

The time-dependent response is characterized by the deviatoric terms, as shown below:

$$
\sigma(t)=\int_{0}^{t} G(t-\tau) \frac{d_{\varepsilon}}{d_{\tau}} d_{\tau}
$$

The above integral is evaluated for current time $t$ on the basis of past time $\tau$. $G(t-\tau)$ is not a constant value, and it can be represented by a Prony series, as shown below:

$$
G(t)=G_{0} \sum_{i=1}^{n} \omega_{i} e^{-\frac{t}{\lambda_{i}}}
$$

where $\omega_{i}$ is the relative moduli, and $\lambda_{i}$ is the reduced time used to describe the shift time due to temperature [17].

The effect of the thermo-rheological simplicity (TRS) is described by the William-Landel-Ferry (WLF) shift function, as shown below:

$$
\log (A(T(\tau)))=\frac{c_{1}\left(T-T_{\tau}\right)}{c_{2}+T-T_{\tau}}
$$

where $T_{\tau}$ is the glass transition temperature, and $c_{1}$ and $c_{2}$ are the material constants.

In the simulation, the properties of the soda-lime preform are listed in Table 1 [18]. The parameters of the Generalized Maxwell model of soda-lime glass are listed in Table 2 [19]. A typical microstructure is molded in Abaqus/Standard. Figure 5 shows the two dimensional (2D) simulation model of GMP for a rectangle microstructure. The bottom model is fixed, and the pressing process is achieved by adding a force boundary condition on the $\mathrm{RP}_{\text {top }}$ which is a coupling constraint with the top model. In order to facilitate the simulation convergence, the shape bottom corner of the top model is rounded with a radius of $0.5 \mu \mathrm{m}$, while the sharp angle of the valley is kept as the actual size. $H_{1}=22 \mu \mathrm{m}$ is set 
to conform to the actual groove depth on the core mold. The top and bottom molds are both modeled as rigid objects. Since each microstructure is symmetrical, a half model is built for simplicity. In order to alleviate the mesh distortion during deformation, the meshes around the bottom corner of the top model are densified. Friction interactions between the glass and the molds are both modeled by the Coulomb friction model, and the friction coefficient $f$ is fixed at 0.1. According to [20], the appropriate model temperature is $620{ }^{\circ} \mathrm{C}$; the range of temperature studied in the simulation was between 620 and $660^{\circ} \mathrm{C}$. Since the normal maximum stress was below $10 \mathrm{MPa}$ in the majority of glass simulation reports, a constant force was set in the simulation to guarantee that.

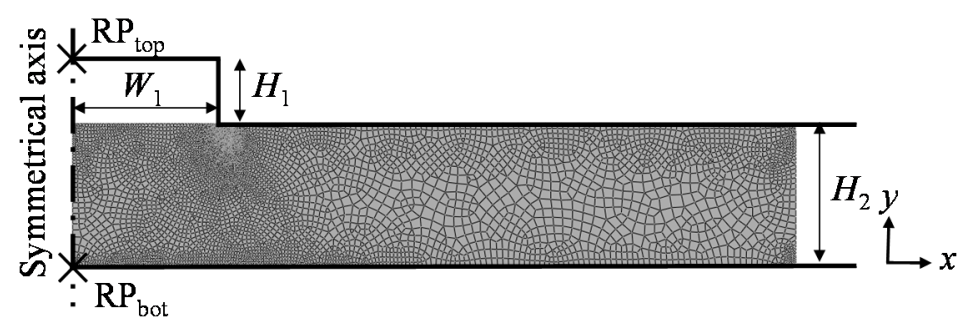

Figure 5. Two dimensional (2D) simulation model for GMP of rectangle microstructure. $\mathrm{RP}_{\text {top }}$ and $\mathrm{RP}_{\text {bot }}$ are the coupling constraint with the top and bottom model, respectively.

Table 1. The thermal and mechanical properties of soda-lime preform. Data from [18].

\begin{tabular}{cc}
\hline Property & Value \\
\hline Module of elasticity, $E(\mathrm{GPa})$ & 62 \\
Module of rigidity, $G(\mathrm{GPa})$ & 25.4 \\
Possion's Ratio, $v$ & 0.22 \\
Density, $\rho\left(\mathrm{kg} / \mathrm{m}^{3}\right)$ & 2500 \\
Specific Heat, $\mathrm{cp}(\mathrm{J} / \mathrm{kg} \cdot \mathrm{K}))$ & 880 \\
Thermal Conductivity, $\mathrm{K}(\mathrm{W} /(\mathrm{m} \cdot \mathrm{K}))$ & 0.937 \\
Glass Transition Temperature, $T_{\mathrm{g}}\left({ }^{\circ} \mathrm{C}\right)$ & 550 \\
Softened temperature, $T_{\mathrm{s}}\left({ }^{\circ} \mathrm{C}\right)$ & 720 \\
\hline
\end{tabular}

Table 2. The parameters of the Generalized Maxwell model. Data from [19].

\begin{tabular}{ccc}
\hline Term No. & Reduced Time $\boldsymbol{\lambda}_{\mathbf{i}}$ (s) & Relative Moduli $\omega_{\mathbf{i}}$ \\
\hline 1 & $8.0790 \times 10^{-5}$ & $5.52214 \times 10^{-2}$ \\
2 & $1.4580 \times 10^{-3}$ & $8.20598 \times 10^{-2}$ \\
3 & $1.8460 \times 10^{-2}$ & $1.21502 \times 10^{-1}$ \\
4 & $2.0380 \times 10^{-1}$ & $2.28594 \times 10^{-1}$ \\
5 & $9.1391 \times 10^{-1}$ & $2.86077 \times 10^{-1}$ \\
6 & 4.0130 & $2.26545 \times 10^{-1}$ \\
\hline
\end{tabular}

\section{Simulation Results and Discussion}

\subsection{Typical Stress Distribution in Molding Process}

Due to the influence of creep characteristics, for a given force and temperature, the filling shape varies with the increasing holding time, as shown in Figure 6. When the holding time was $40 \mathrm{~s}$, the maximum stress location was around the bottom corner of the top mold, and a swell was successfully molded, as shown in Figure 6a. When it increased to $60 \mathrm{~s}$, the swell could touch the top ceiling of the rectangle top mold, and another high-stress location was generated at the end of the contact area, as shown in Figure 6b. When it increased to $100 \mathrm{~s}$, the high deformation of the glass by the squeeze of the mold made it contact with the side wall of the mold, and the third high-stress area was formed, as shown in Figure 6c. When the time increased further, the high-stress areas near 
both the ceiling and side wall gradually approached to the right corner, and became one, as shown in Figure $6 \mathrm{~d}$. The maximum stress in the four movements was around 6.19 $\mathrm{MPa}$.
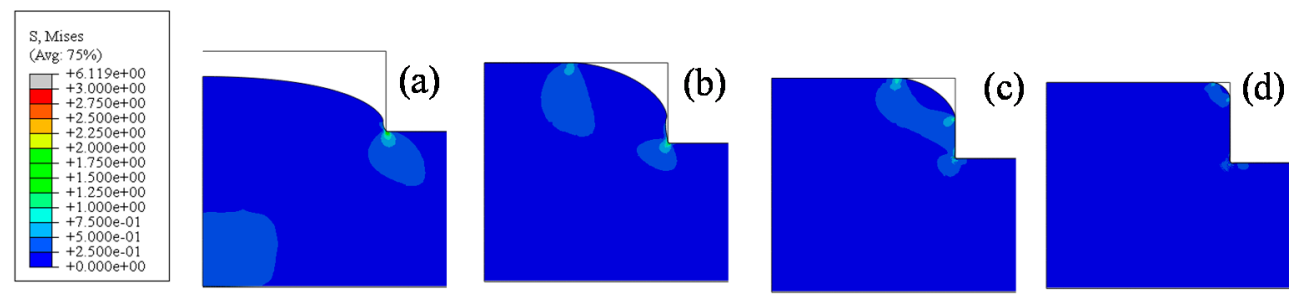

Figure 6. Stress distribution at $640{ }^{\circ} \mathrm{C}($ a) $40 \mathrm{~s}$, (b) $80 \mathrm{~s}$, (c) $100 \mathrm{~s}$ and (d) $140 \mathrm{~s}$.

\subsection{Influence of Temperature $T$}

The influence of the filling ratio is shown in Figure 7. It is evident that the replication ratio increased with the pressing time due to the glass characteristic of stress relaxation and creep under the high-temperature molding process. The partial filling ratios were obtained under the investigated holding time range when the temperature was 620 and $630{ }^{\circ} \mathrm{C}$, while when temperature increased above $640{ }^{\circ} \mathrm{C}$, the replication ratio rose dramatically and achieved complete replication in a short time. The higher temperature, the shorter the hold time required. It is worth pointing out that high temperature can shorten the holding time; in the meantime, it increased the heating time and the risk of adhesion between the mold and glass. Therefore, in practice, an appropriate holding time and temperature should be chosen in GMP. In order to provide more details about molded morphologies, the molded profiles of the simulation at $60 \mathrm{~s}$ were extracted and are shown in Figure 8 correspondingly.

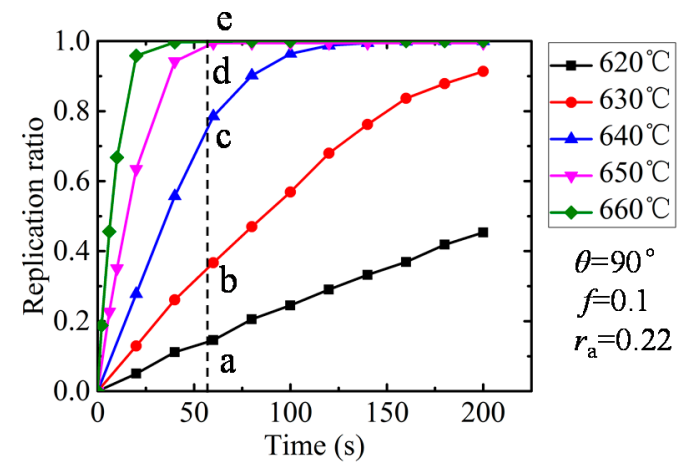

Figure 7. Influence of temperature on replication ratio.

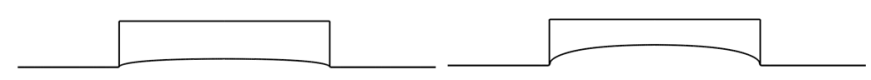

(a) $\mathrm{T}=620^{\circ} \mathrm{C}$

(b) $T=630^{\circ} \mathrm{C}$

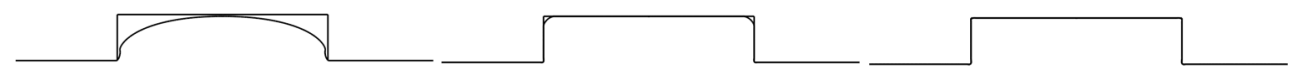

(c) $\mathrm{T}=640^{\circ} \mathrm{C}$

(d) $T=650^{\circ} \mathrm{C}$

(e) $T=660^{\circ} \mathrm{C}$

Figure 8. Molded profiles by simulation at different temperature $\left(\theta=90^{\circ}, r_{\mathrm{a}}=0.22\right)$. (a) $\mathrm{T}=620^{\circ} \mathrm{C}$, (b) $\mathrm{T}=630{ }^{\circ} \mathrm{C}$, (c) $\mathrm{T}=640{ }^{\circ} \mathrm{C}$, (d) $\mathrm{T}=650{ }^{\circ} \mathrm{C}$ and (e) $\mathrm{T}=660^{\circ} \mathrm{C}$. 


\subsection{Influence of Aspect Ratio $r_{a}$}

The influence of the replication ratio is shown in Figure 9. All the results were extracted at a holding time of $60 \mathrm{~s}$. It is obvious that the replication increases with the pressing temperature, while it drops with the aspect ratio. When the aspect ratio increased from 0.22 to 1.00 , it fell dramatically, and when the aspect ratio increased further, a moderate drop was witnessed. Since glass can fill the mold curve completely at 640 and $650{ }^{\circ} \mathrm{C}$ when the aspect ratio is below 0.44 , the pattern is not obvious for the two high-temperature curves. The main reason is that the viscoelastic glass tends to flow in the place of small resistance. When the aspect ratio is high, the glass flowing inside is supposed to be confronted with high resistance, thereby lowering the replication ratio. The molded profiles by simulation at the temperature of $640{ }^{\circ} \mathrm{C}$ were extracted and are shown in Figure 10 correspondingly. In order to provide more details, the molded areas in Figure 10d,e are enlarged. It is obvious that the higher the aspect ratio, the smaller the replication ratio.

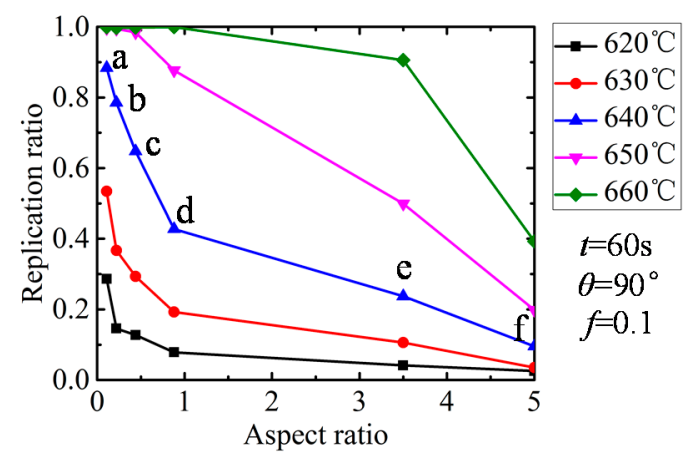

Figure 9. Influence of aspect ratio on replication ratio.

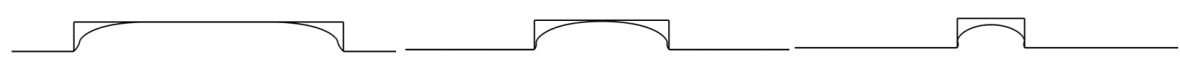

(a) $r_{\mathrm{a}}=0.11$

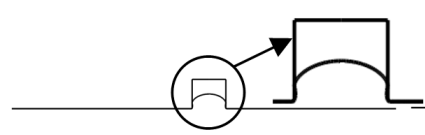

(d) $r_{\mathrm{a}}=0.88$ (b) $r_{\mathrm{a}}=0.22$

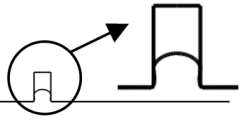

(e) $r_{\mathrm{a}}=3.52$ (c) $r_{\mathrm{a}}=0.44$

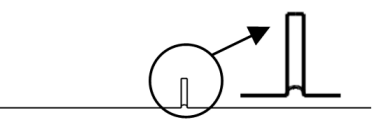

(f) $r_{\mathrm{a}}=5.00$

Figure 10. Molded profiles by simulation at different aspect ratios $\left(t=60 \mathrm{~s}, \theta=90^{\circ}\right)$. (a) $r_{\mathrm{a}}=0.11$, (b) $r_{\mathrm{a}}=0.22,(\mathbf{c}) r_{\mathrm{a}}=0.44$, (d) $r_{\mathrm{a}}=0.88,(\mathbf{e}) r_{\mathrm{a}}=3.52$ and (f) $r_{\mathrm{a}}=5.00$.

\subsection{Influence of Side Wall Angle $\theta$}

The influence of the side wall angle on the replication ratio is shown in Figure 11. All the curves witnessed a slight drop when the side wall angle increased from $70^{\circ}$ to $90^{\circ}$, except for the two curves which were equal to or above $640^{\circ} \mathrm{C}$ due to their complete filling. The pattern can be attributed to the flow resistance as well. The flow in a smaller side wall angle groove is supposed to be confronted with lower resistance. However, the influence is almost negligible compared to the influence of the temperature and aspect ratio. The molded profiles by simulation at the temperature of $640{ }^{\circ} \mathrm{C}$ were extracted and are shown in Figure 12 correspondingly. It is apparent that the influence of the side wall angle on the replication ratio is negligible. 


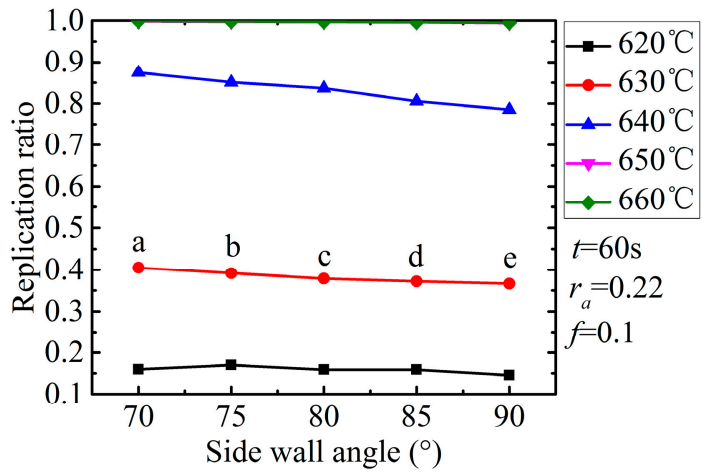

Figure 11. Influence of side wall angle on replication ratio.

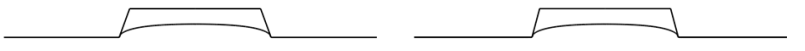

(a) $\theta=70^{\circ}$

(b) $\theta=75^{\circ}$

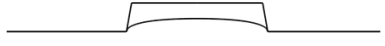

(c) $\theta=80^{\circ}$

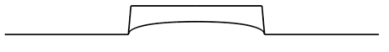

(d) $\theta=85^{\circ}$

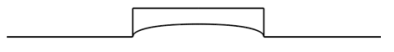

(e) $\theta=90^{\circ}$

Figure 12. Molded profiles by simulation at different angle degrees $\left(t=60 \mathrm{~s}, r_{\mathrm{a}}=0.22\right)$. (a) $\theta=70^{\circ}$, (b) $\theta=75^{\circ}$, (c) $\theta=80^{\circ}$, (d) $\theta=85^{\circ}$, and (e) $\theta=90^{\circ}$.

\section{Experimental Results and Verification}

In order to verify the simulation results, the corresponding experiment had to be conducted. Basically, there were four factors contributing the deviation between the predicted and experimental results as below:

(1) Step

The models only simulated the pressing step due to simplification, while the experiment consisted of four steps, i.e., heating, pressing, annealing and cooling.

(2) Constitutive model

The constitutive model was based on the related reference. Although they shared the same material brand name, the constitutive properties might be different to some extent as well.

(3) Mold geometry

The mold geometry in the simulation was simplified so the side wall angle was $90^{\circ}$ and the corner radius was rounded with a radius of $0.5 \mu \mathrm{m}$.

(4) Glass thickness

The glass thickness in the experiment was around $500 \mu \mathrm{m}$, while it was $50 \mu \mathrm{m}$ in the simulation due to simplification.

Therefore, it is hard to achieve direct quantitative verification at this stage. In this paper, the qualitative and indirect quantitative verification were conducted.

Figure 13 shows the 3D morphology of the molded preform pressed at different temperatures, i.e., 620,630 and $640{ }^{\circ} \mathrm{C}$. A high temperature can lead to the high flowability of the preform, which makes it easy to deform. Comparing the three photos, it is obvious that the higher the pressing temperature, the higher the swell height. The maximum height was $12.1 \mu \mathrm{m}$ at $620^{\circ} \mathrm{C}$, while it changed to 15.5 and 
$22.1 \mu \mathrm{m}$ at 630 and $640{ }^{\circ} \mathrm{C}$, respectively. The trend is consistent with the results in Figure 7. In addition, when only one photo was analyzed, it is obvious that the wider the groove, the higher the swell height. The trend is consistent with the results in Figure 9.

In order to provide more details of the molded preform, a track line is drawn in each photo in Figure 13, and the corresponding 2D profiles are shown in Figure 14. All molded shapes are similar to the simulation result in that they appear to be upward salient arcs before achieving the full filled condition. To evaluate the change in the replication ratio versus the aspect ratio quantitatively, their heights in Figure 15 are recorded, and the height change rate was defined as the height of the aspect ratio 0.44 divided by that of 0.11 . Figure 15 demonstrates the height change ratio versus the aspect ratio. It indicates that there is an obvious influence of the aspect ratio on the swell height. Specifically, the height generated at the aspect ratio of 0.44 was around $65 \%$ of that at the aspect ratio of 0.11 . The deviation error between the simulation and experimental results is around $10 \%$, although the height change ratio is higher from predicted results. Therefore, the simulation results are verified by the experimental results successfully, and it proves again that the change in aspect ratio has an important influence on the replication ratio.

(a)

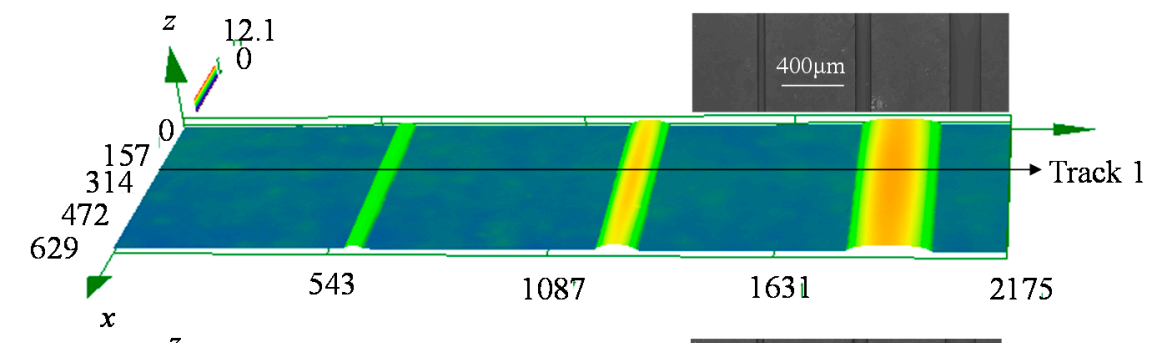

(b)

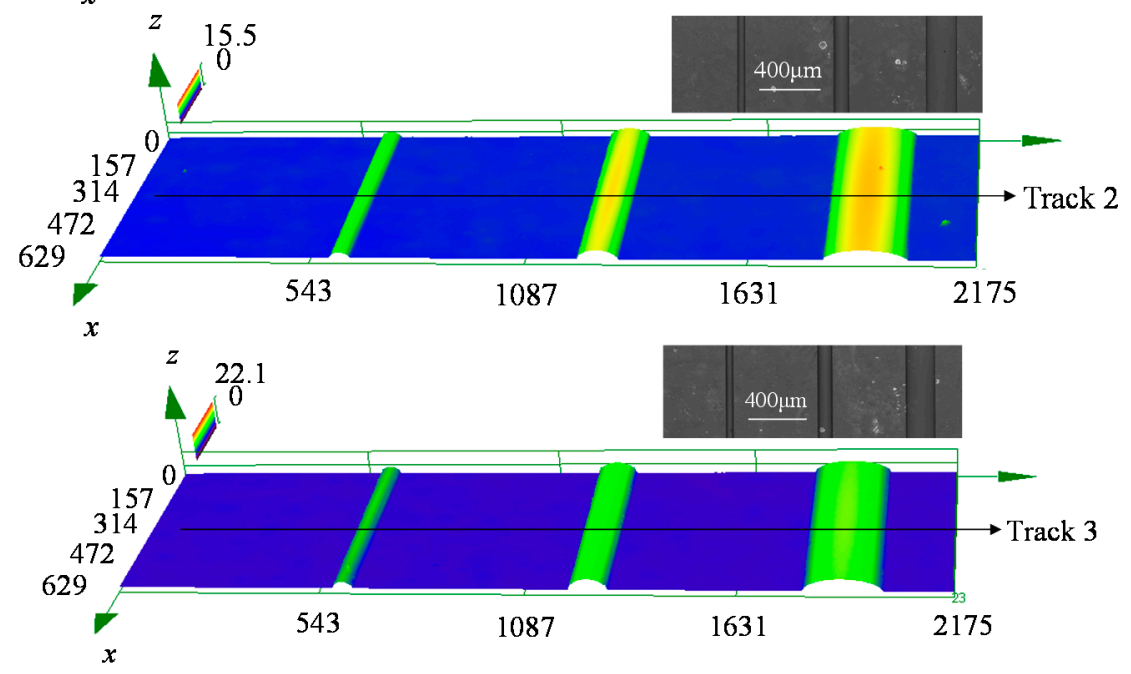

Figure 13. Three dimensional (3D) morphology of molded preform (press time $60 \mathrm{~s}$, pressures $0.3 \mathrm{MPa}$. (a) $\mathrm{T}=620^{\circ} \mathrm{C}$, (b) $\mathrm{T}=630^{\circ} \mathrm{C}$ and (c) $\mathrm{T}=640^{\circ} \mathrm{C}$.

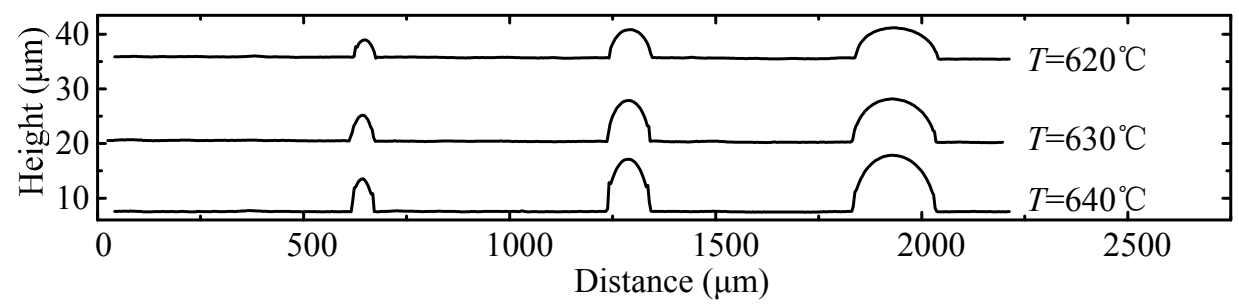

Figure 14. The two dimensional (2D) profiles of the molded preform. 


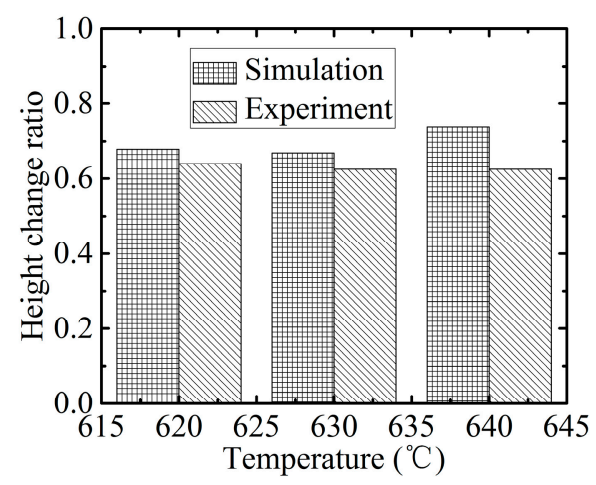

Figure 15. The height change ratio versus aspect ratio.

\section{Conclusions}

The paper investigated the formation process of cuboid microprotrusions by the glass molding process, and the following conclusions can be made:

(1) The maximum stress was located around the bottom corner of the top mold. High stress was generated when the glass contacted the ceiling and side wall of the mold, and it gradually approached the unfilled corner when the molding time was increased further.

(2) The replication ratio dramatically increased with the pressing temperature, while the pattern was reversed with the increase of the aspect ratio. The influence of the angle degree was negligible, though some slight decrease of the replication ratio with the increase of the degree angle was witnessed.

(3) The results from GMP experiments confirmed that the change in the aspect ratio had an important influence on the replication ratio. By comparing the experimental and predicted results, the established FEM model was verified.

Acknowledgments: This project is supported by the National Natural Science Foundation of China (Grant No. U1537208) and the National High Technology Research and Development Program of China (863) Grant No. 2015AA043601.

Author Contributions: Jing Chen conceived and designed the experiments; Tao Wang performed the experiments and wrote the paper; Lu Song contributed to the fabrication of the core mold; Tianfeng Zhou provided valuable suggestions about the paper.

Conflicts of Interest: The authors declare no conflict of interest. The founding sponsors had no role in the design of the study; in the collection, analyses, or interpretation of data; in the writing of the manuscript, and in the decision to publish the results.

\section{References}

1. Chen, Q.; Chen, Q.; Maccioni, G. Fabrication of microfluidics structures on different glasses by simplified imprinting technique. Curr. Appl. Phys. 2013, 13, 256-261. [CrossRef]

2. Chen, Q.; Li, G.; Jin, Q.H.; Zhao, J.L. A rapid and low-cost procedure for fabrication of glass microfluidic devices. J. Microelectromech. Syst. 2007, 16, 1193-1200. [CrossRef]

3. Park, J.H.; Lee, N.E.; Lee, J.; Park, J.S.; Park, H.D. Deep dry etching of borosilicate glass using $\mathrm{SF}_{6}$ and $\mathrm{SF}_{6} / \mathrm{Ar}$ inductively coupled plasmas. Microelectron. Eng. 2005, 82, 119-128. [CrossRef]

4. Nieto, D.; Couceiro, R.; Aymerich, M.; Lopez-Lopez, R.; Abal, M.; Flores-Arias, M.T. A laser-based technology for fabricating a soda-lime glass based microfluidic device for circulating tumour cell capture. Colloids Surf. $B$ 2015, 134, 363-369. [CrossRef] [PubMed]

5. Lin, Y.C.; Lee, C.C.; Lin, H.S.; Hong, Z.H.; Hsu, F.C.; Hung, T.P.; Lyu, Y.T. Fabrication of Microfluidic Structures in Quartz via Micro Machining Technologies. Available online: http:/ /link.springer.com/article/ 10.1007/s00542-015-2717-y (accessed on 13 Feburary 2017). 
6. He, P.; Li, L.; Li, H. Compression molding of glass freeform optics using diamond machined silicon mold. Manuf. Lett. 2014, 2, 17-20. [CrossRef]

7. Zhou, T.F.; Yan, J.W.; Kuriyagawa, T. Comparing microgroove array forming with micropyramid array forming in the glass molding press. Key Eng. Mater. 2010, 447, 361-365. [CrossRef]

8. Jain, A.; Yi, Y.A. Finite element modeling of structural relaxation during annealing of a precision-molded glass lens. J. Manuf. Sci. Eng. 2006, 128, 683-690. [CrossRef]

9. Zhou, T.F.; Yan, J.W.; Masuda, J.; Tsunemoto, K. Ultraprecision mass fabrication of aspherical Fresnel lens by glass molding press. Adv. Mater. Res. 2011, 325, 713-718. [CrossRef]

10. He, P.; Wang, F.; Li, L.K.; Georgiadis, K.; Dambon, O.; Klock, F.; Yi, A.Y. Development of a low cost high precision fabrication process for glass hybrid aspherical diffractive lenses. J. Opt. 2010, 13, 1-8. [CrossRef]

11. Jain, A. Experimental Study and Numerical Analysis of Compression Molding Process for Manufacturing Precision Aspherical Glass Lenses. Ph.D. Thesis, The Ohio State University, Columbus, OH, USA, June 2006.

12. Liu, C.; Li, J.M.; Liu, J.S.; Wang, L.D. Deformation behavior of solid polymer during hot embossing process. Microelectron. Eng. 2010, 87, 200-207. [CrossRef]

13. Jain, A.; Firestone, G.C.; Yi, A.Y. Viscosity measurement by cylindrical compression for numerical modeling of precision lens molding process. J. Am. Ceram. Soc. 2005, 88, 2409-2414. [CrossRef]

14. Chen, X.; Cui, D.F.; Liu, C.C.; Li, H. Microfluidic chip for blood cell separation and collection based on crossflow filtration. Sens. Actuators B Chem. 2008, 130, 216-221. [CrossRef]

15. Ji, H.M.; Chen, S.Y.; Heng, C.K.; Lim, T.M.; Yobas, L. Silicon-based microfilters for whole blood cell separation. Biomed. Microdevices 2008, 10, 251-257. [CrossRef] [PubMed]

16. Gossett, D.R.; Weaver, W.M.; Mach, A.J.; Hur, S.C.; Tse, H.T.K.; Lee, W. Label-free cell separation and sorting in microfluidic systems. Anal. Bioanal. Chem. 2010, 397, 3249-3267. [CrossRef] [PubMed]

17. Ryuichi, K.; Zhou, T.F.; Shimada, K.; Mizutani, M.; Kuriyagawa, T. Ultraprecision glass molding press for microgrooves with different pitch sizes. Int. J. Automot. Technol. 2013, 7, 678-685.

18. Joshi, D. Thermo-Mechanical Characterization of Glass and its effect on Predictions of Stress State, Birefringence and Fracture in Precision Glass Molded Lenses. Ph.D. Thesis, Clemson University, Clemson, SC, USA, December 2014.

19. Duffrene, L.; Gy, R.; Burlet, H.; Piques, R. Multiaxial Linear Viscoelastic Behavior of Soda-Lime-Silica Glass Based on a Generalized Maxwell Model. Soc. Rheol. 1997, 41, 1021-1038. [CrossRef]

20. Huang, C.Y.; Kuo, C.H.; Hsiao, W.T.; Huang, K.C.; Tseng, S.F.; Chou, C.P. Glass biochip fabrication by laser micromachining and glass-molding process. J. Mater. Process. Technol. 2012, 212, 633-639. [CrossRef]

(C) 2017 by the authors. Licensee MDPI, Basel, Switzerland. This article is an open access article distributed under the terms and conditions of the Creative Commons Attribution (CC BY) license (http:/ / creativecommons.org/licenses/by/4.0/). 